\title{
Prospects of using new technologies in Russia's electric power industry to comply with international commitments to reduce $\mathrm{CO}_{2}$ emissions
}

\author{
Alexey Tchemezov ${ }^{1,2^{*}}$, Elena Chemezova $^{3}$, Anton Syromyatnikov ${ }^{2}$ \\ ${ }^{1}$ Melentiev Energy Systems Institute of Siberian Branch of Russian Academy of Sciences, 664033 Irkutsk, Lermontov str., 130, \\ Russia \\ ${ }^{2}$ Irkutsk National Research Technical University, 664072 Irkutsk, Lermontov str., 83, Russia \\ ${ }^{3}$ Exploration College of Irkutsk National Research Technical University, 664072 Irkutsk, Lermontov str., 104, Russia
}

\begin{abstract}
This study addresses the methodology of projecting the electric power industry developments, taking into account environmental constraints. I obtained quantitative assessments of long-term electric power industry development in a Russian region, determined the emission of greenhouse gases from fuel combustion at thermal power plants (TPPs), and the efficiency of technologies to reduce greenhouse gas emissions in the electric power industry.
\end{abstract}

\section{Introduction}

Presently, when planning and programming economy development of the countries and regions, the global climate change problem related to emissions of greenhouse gases - carbon dioxide, $\mathrm{CO} 2$ being the main among the latter - at fuel combustion is regarded the most acute [1]. The constraints on its emission imposed by the Paris Agreement, in fact, define the boundaries impeding the power engineering development, and, consequently, they restrain the economy development, especially in developing countries. At present, it is difficult to estimate how much these constraints are justified, because investigations into the anthropogenous emission effect on the climate and its change have not been completed yet, with the preliminary conclusions being ambiguous and even contradictory [2].

In Russia, a number of Federal Laws, according to which greenhouse gas emissions should be reduced to $75 \%$ of the 1990 level by 2020 , and to $70 \%$ by 2030 [3], have been passed.

There is no real alternative to fossil hydrocarbon fuel as a primary energy carrier over a long perspective. Reducing the carbon dioxide emissions into the atmosphere may be achieved by:

- $\quad$ active promotion of energy-saving technologies;

- increase in electric power production efficiency through improving thermodynamic cycles, equipment, fuel combustion techniques, use of fuel elements, etc.;

- introduction of multi-purpose power technological installations that, besides electric power, produce additional marketable products (for example, through the catalytic synthesis methods, etc.) increasing the fuel usage coefficient as compared with separate production of electric power and those products;
- switching to fuels containing smaller carbon amount (replacing coal with natural gas, or oil motor fuel with hydrogen);

- $\mathrm{CO}_{2}$ recovery in the power installation cycle with its subsequent durable disposal (sequestering).

\section{Modelling long-term development of Russia's electric power industry}

Figures and tables, as originals of good quality and well contrasted, are to be in their final form, ready for reproduction, pasted in the appropriate place in the text. Try to ensure that the size of the text in your figures is approximately the same size as the main text (10 point). Try to ensure that lines are no thinner than 0.25 point.

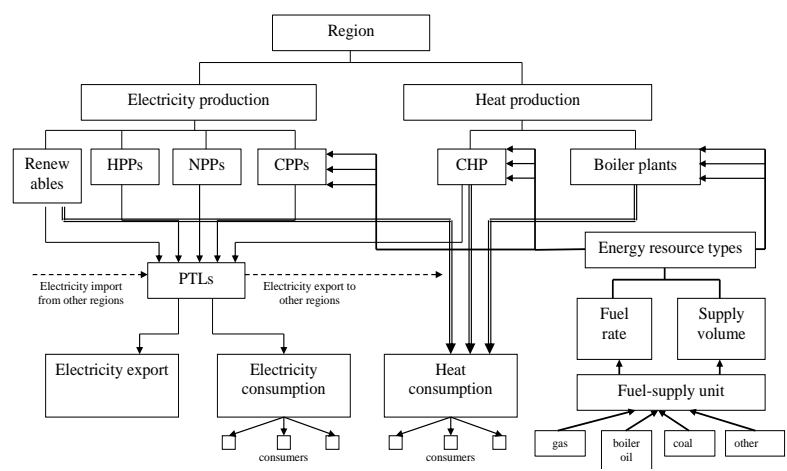

Fig. 1. Structure of the model for production, distribution, and consumption of electric and district heating

As per the above model construction principle, each energy carrier produced at this or that stage is appropriated by the corresponding equation in the model, whereas each power plant is appropriated by a variable: 


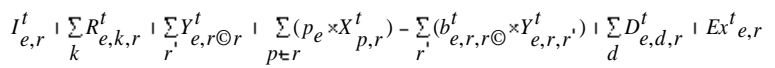

for all: $e \in 1, \ldots, E ; r \in 1, \ldots, r^{\prime} \ldots, R ; t \in 1, \ldots, T$, where: $I_{e, r}^{t}$ is the energy carrier $e$ import to the region $r$ in year $t ; R_{e, k, r}^{t}$ is the extraction of the given energy carrier $e$ by all plants $k$ in the territory of the region $r$ $(k \in r)$ in year $t ;{ }_{e, r^{\prime} r}^{t}$ is possible import of the energy carrier $e$ from other regions $r^{\prime} ; x_{p, r}^{t}$ is the production capacity of the power plant $p$ in the region $r(p \in r)$ in year $t ; p_{e}$ is the coefficient determining the output (consumption) of the energy carrier $e$ at the plant $p\left(p_{e}\right.$ $=-1 / f_{p}$, if the energy carrier is consumed, $p_{e}=1$, if the energy carrier is produced); $Y_{e, r, r^{\prime}}^{t}$ are possible deliveries of the energy carrier $e$ to other regions $r^{\prime}$ considering transport losses $b_{e, r, r^{\prime}}^{t}$ in year $t ; D_{e, d, r}^{t}$ is the consumption of the end energy carrier $e$ by customers' categories $d$ in the region $r$ in year $t ;{ }_{E x}^{t} t_{e, r}$ is the energy carrier $e$ export from the region $r$ in year $t$.

All the power plants are split into operating $\left(\operatorname{RESS}_{p, r}^{t}\right)_{t=1}$ by the settling period start, and newly-built plants $\left(X_{p, r}^{t}\right)_{t, 1}$. For the operating plants, I specify the dynamics of their possible retirement by stages of the settling period $\left(\operatorname{RESX}_{p, r}^{t+1} \subseteq \operatorname{RESX} X_{p, r}^{t}\right)$, and creation of new production capacities. Newly-commissioned capacities at each temporal stage may be restrained and should retire as the standard life comes to an end. To consider the dynamics factor, I introduce the capacity transport equations for each power plant by stages $t$ of the settling period $T$. For a separate plant $p$ in the region $r$, this equation looks like:

$$
X_{p, r}^{t}=R E S X_{p, r}^{t}, \sum_{b<t} \min \left(R L_{p}^{b, t} / n_{t}, 1\right) \times X_{p, r}^{b}
$$

for all $p \in 1, \ldots, P$,

where: ${ }^{X_{p, r}^{t}}$ is the power plant $p$ capacity in the region $r$ in year $t ;{ }^{R E S X_{p, r}^{t}}$ is the residual capacity of the plant $p$ in the region $r$ at the stage $t$, that was commissioned by the settling period start; $R L_{p}^{b, t}$ is the number of years, over which the power plant $p$ capacity built at the stage $b$ persists (proceeding from the standard life) at the stage $t$; ${ }^{n} t$ is the number of years at the stage $t ;{ }_{p, r}^{b}$ is the power plant $p$ capacity introduced at the stage $b$ in the region $r$;

In general case, the technological aspect of the power plant (technology) is described by the following metrics: coefficients determining the consumption and production of energy carriers by the given plant (technology); power installation efficiency coefficient; operation mode; plant life.
As the economic metrics of power plants, I use: specific constant and variable costs related to maintaining power plant capacities and to producing power resources and energy carriers; specific holdings necessary for building (renovating) power plant capacities, energy-saving technologies and emission reduction technologies.

\section{Assessing the efficiency of using new technologies in Russia}

Effective (in terms of the $\mathrm{CO}_{2}$ emission reduction, included) is perfecting the TPP energy production based on $[4,7,8]$ :

- introducing coal power-generating units at supercritical (41\% eff.) and supercritical (46\% eff.) steam parameters;

- $\quad$ introducing steam-gas plants (55-60\% eff.);

- using boilers with circulating fluidized bed at lowgrade-fuel combustion;

- using fuels with an increased calorific value, and natural gas;

- using technologies of $\mathrm{CO}_{2}$ recovery and disposal.

To assess the performance of the offered methodical approach, I address two scenarios for the Irkutsk Oblast electric power industry development: optimistic and basic $[5,6]$.

The power consumption was projected by considering the economy development and the population perspective metrics. Inasmuch as the planned long-term regional major energy-intensive investment projects, the projection for the need in electric power was performed separately for the industries and services (developed for today) and for new industries (projects) [7-10]. 
Table 1. Projection of the electric power and heat production in Irkutsk Oblast

\begin{tabular}{|c|c|c|c|c|c|c|c|c|c|c|}
\hline & $\mathbf{1 9 9 0}$ & $\mathbf{2 0 0 0}$ & $\mathbf{2 0 1 0}$ & $\mathbf{2 0 1 5}$ & \multicolumn{2}{|c|}{$\mathbf{2 0 2 0}$} & \multicolumn{2}{|c|}{$\mathbf{2 0 2 5}$} & \multicolumn{2}{|c|}{$\mathbf{2 0 3 0}$} \\
\hline & & & & & $\mathbf{0 . s .}$ & b.s. & $\mathbf{0 . s .}$ & b.s. & 0.s. & b.s. \\
\hline $\begin{array}{c}\text { Electricity production, } \\
\text { bil. kW·h }\end{array}$ & $\mathbf{6 7 , 1}$ & $\mathbf{5 4 , 5}$ & $\mathbf{6 2 , 4}$ & $\mathbf{4 8 , 0}$ & $\mathbf{6 4 , 3}$ & $\mathbf{5 6 , 9}$ & $\mathbf{7 3}$ & $\mathbf{5 7 , 5}$ & $\mathbf{7 7}$ & $\mathbf{6 0 , 6}$ \\
\hline Hydro Power Plants & 47,5 & 47,3 & 49,3 & 35,9 & 46,3 & 46,3 & 46,3 & 46,3 & 48,6 & 48,6 \\
\hline Thermal Power Plants & 19,6 & 7,2 & 13,1 & 12,1 & 18,0 & 10,6 & 26,7 & 11,2 & 28,4 & 12,0 \\
\hline $\begin{array}{c}\text { Thermal energy } \\
\text { production, mln. GCal }\end{array}$ & $\mathbf{7 2 , 6}$ & $\mathbf{5 4 , 7}$ & $\mathbf{4 9 , 1}$ & $\mathbf{4 1 , 2}$ & $\mathbf{4 6}$ & $\mathbf{4 4}$ & $\mathbf{5 0}$ & $\mathbf{4 6}$ & $\mathbf{5 9}$ & $\mathbf{5 4}$ \\
\hline
\end{tabular}

As per the electric power industry development scenarios, we calculated the $\mathrm{CO}_{2}$ emissions from fuel combustion at TPPs (Table 2).

Table 2. $\mathrm{CO}_{2}$ emission volume at boiler-furnace fuel (BFF) combustion, mln. tonnes*

\begin{tabular}{|c|c|c|c|c|c|c|c|c|c|c|}
\hline & $\mathbf{1 9 9 0}$ & $\mathbf{2 0 0 0}$ & $\mathbf{2 0 1 0}$ & $\mathbf{2 0 1 5}$ & \multicolumn{2}{|c|}{$\mathbf{2 0 2 0}$} & \multicolumn{2}{|c|}{$\mathbf{2 0 2 5}$} & \multicolumn{2}{|c|}{$\mathbf{2 0 3 0}$} \\
\hline $\begin{array}{c}\text { Thermal power } \\
\text { plants }\end{array}$ & $\mathbf{3 5 , 4}$ & $\mathbf{2 2 , 4}$ & $\mathbf{2 2 , 7}$ & $\mathbf{2 0 , 7}$ & $\mathbf{2 6 , 4}$ & $\mathbf{2 3 , 3}$ & $\mathbf{3 6 , 3}$ & $\mathbf{3 3 , 3}$ & $\mathbf{3 2 , 7}$ & $\mathbf{3 0 , 9}$ \\
\hline including coal & 32,0 & 19,6 & 19,3 & 17,9 & 22,9 & 19,9 & 32,8 & 29,8 & 22,6 & 21,8 \\
\hline gas & 0 & 0 & 0 & 0 & 0 & 0 & 0 & 0 & 6,6 & 5,7 \\
\hline oil & 0,6 & 0,3 & 0 & 0 & 0,09 & 0,09 & 0,09 & 0,09 & 0,1 & 0,1 \\
\hline other, etc & 2,8 & 2,52 & 3,4 & 2,8 & 3,4 & 3,4 & 3,4 & 3,4 & 3,4 & 3,4 \\
\hline
\end{tabular}

The $\mathrm{CO}_{2}$ emissions from TPP fuel combustion will exceed the 1990 level by 2025, and reach 36,3 and 33,3 mln. t. in the optimistic and basic scenarios, respectively. By 2030, they decrease provided new power stations are commissioned.

However, if one considers further decrease in the $\mathrm{CO}_{2}$ emissions, it is necessary to change the structure of the consumed fuel (to use natural gas), or to use new technologies of steam-gas plants (integrated gasification combined cycle (IGCC), etc.).

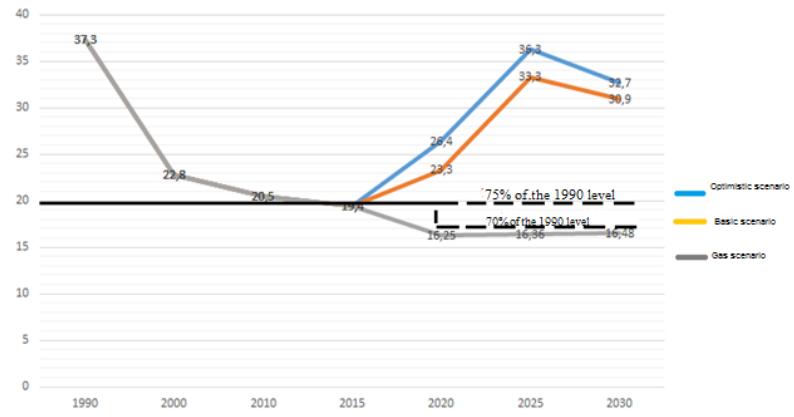

Fig. 2 Projection for the $\mathrm{CO}_{2}$ emissions from TPP fuel combustion, mln. tonnes

To implement President's Decrees on the $\mathrm{CO}_{2}$ emission reduction in any scenario for the Irkutsk Oblast electric power industry development, it is necessary to apply additional measures. Considering the capital investments and operational costs, TPP switching to natural gas is the most inexpensive way (of all the above processes) to reduce $\mathrm{CO}_{2}$ emissions. Herewith, the $\mathrm{CO}_{2}$ reduction may reach 20-22 $\mathrm{mln}$. tonnes (Figure 2).

\section{Conclusion}

The proposed methodical approach enables to select an optimal version for Russia's (regions') electric power industry development, considering environmental constraints.

I provided an example of assessing the $\mathrm{CO}_{2}$ emission reduction technology efficiency in Irkutsk Oblast, and showed the necessity to change the structure of the BFF consumption and TPP switching to natural gas.

\section{References}

1. A. Tchemezov, B. Saneev, A. Lagerev Outlooks of Russia's power industry development in the $21 \mathrm{st}$ century and greenhouse gas emissions // International Journal of Energy Technology and Policy. 2003, Vol. 20, No. 4, pp. 382-392. doi: 10.1504/IJGEI.2003.004411.

2. National system of greenhouse gas cap-and-trade. Moscow, 2011, P. 40, in Russian.

3. 2013 September 30 Russian Federation President's Decree No. 752 «On reducing greenhouse gas emissions» // Official website of Russia's President, 2013 September 30 [e-resource]. URL: <http://static.kremlin.ru/media/acts/files/0001201310 010043.pdf> (access date: 2018 May 15).

4. B. Saneev, A. Lagerev, V. Khanaeva, and A. Tchemezov Kyoto mechanisms as a tool of expanding the international cooperation to provide energy security of Russia // Izvestiya RAN (Proceedings of the Russian Academy of Sciences. Power Engineering, 2006, No. 3, pp.121-126, in Russian. 
5. On approving the scheme and program for the Irkutsk Oblast electric power industry development over 2017-2021 // Official website of the "Kodeks" LLC, 2016 December 22 [e-resource]. URL: $\langle$ http://docs.cntd.ru/document/441789760> (access date: 2018 May 15).

6. 2010 October 18 Irkutsk Oblast Government Order No. 266-pp «Long-term target program Gasification of Irkutsk Oblast over 2011-2015» // Website of Irkutsk Oblast Government, 2010 November 10 [eresource]. URL: http://irkobl.ru/

7. Prutkovsky E.N., V.S. Varvarskiy, V.I. Gritsenko, et al. Ecological and Energy Aspects of introducing 3rd-generation SGPs with ICG to Power Engineering // Teploenergetika (Thermal Energy Engineering), 1993, No. 11, pp.18-22, in Russian.

8. Stennikov V.A., and S.V. Zharkov. Method of assessing production efficiency by $\mathrm{CO} 2$ emission minimization with the focus on energy supply systems // Al'ternativnaya energetika i ekologiya (Alternative power engineering and ecology), 2017, Nos.16-18, pp.118-132, in Russian.

9. Irkutsk Oblast Fuel and Energy Complex: Current State and Development Perspectives / Ed. by B.G. Saneev and N.A. Voronin. - Moscow: "Energiya" Publishing House, 2013, P. 304, in Russian.

10. Baikal Region Fuel and Energy Complex: Current state, Development Perspectives // Ed. by B.G. Saneev; Russian Academy of Sciences, Siberian Branch, Melentiev Energy Systems Institute. Novosibirsk: GEO Academic Publishers. 2015, P. 176, in Russian. 